\title{
APPLE TREE MODEL OF EMOTION-INVOLVED PROCESSING
}

\section{Jana Kamenická ${ }^{1}$}

\begin{abstract}
The aim of this paper is to summarize the findings of research done in the field of foreign language pedagogy, neuroscience, and psychology with regard to the emotion-cognition relationship. Several studies of qualitative and quantitative nature, which were conducted on teenage and university students, suggest that cognition is strongly affected by emotional experience. Especially positive emotionally competent stimuli experienced when learning a foreign language can contribute to deeper processing and better long-term retention, and at the same time, it is suggested that they have the power to alleviate foreign language anxiety and enhance foreign language enjoyment and the motivation of learners. With regard to these research findings and several cognitive theories, the Apple Tree Model of Emotion-Involved Processing in Foreign Language Learning is proposed and discussed - as well as several ideas on how to emotionally stimulate foreign language learners, which are applicable not only in foreign language classes but also out of the class. Their addictive nature ensures that learners can and do learn the foreign language every day at any time of the day in an authentic language environment - even without realizing it doing it as a hobby.
\end{abstract}

UDC Classification: 81.34, DOI: https://doi.org/10.12955/pss.v2.219

Keywords: emotionally competent stimuli, emotion-involved processing, foreign language pedagogy, TEFL.

\section{Introduction}

The lovers of nature will agree that gardening is an art itself. Although it is often the beautiful flowers and rich harvest that we see and enjoy most of all, the real beauty is not in the final result but in what leads to it - all the work done, time spent, and love and care provided by the gardener. Unfortunately, in foreign language (FL) education, it is often the final result teachers and learners concentrate on, and sufficient care is often neglected. As it is with gardens, to have a rich harvest, it is not enough to ensure just the plants' basic needs - additional nutrition is needed, which can be provided by the gardener only. It is very similar to education. Although there is lots of cognitive content provided, for a high-quality harvest, emotional nutrition is also needed, which, as it seems, is the only type of nutrition that effectively penetrates the whole plant, including its deepest root system.

In this work, we discuss the cognitive theories, which deal with various levels of cognitive processing. However, recent research suggests that emotions experienced when learning are easily remembered, and they have the power to facilitate cognition. Thus, we propose the Apple Tree Model of EmotionInvolved Processing, in which it is suggested that emotions experienced in the learning process act similarly as the nutrition for plants in gardening.

\section{Cognitive Theories}

\section{Dual Coding Theory}

The oldest theory, which forms the basis for our Apple Tree Model, originates probably 2500 years ago (Yates, 1966) when the mnemonic property of imagery was recognized. In fact, imagery can enhance every single step of cognitive processing, namely noticing, encoding, organization, storage, and retrieval of information (Boers \& Lindstromberg, 2008; McPherron \& Randolph, 2014).

This concept was proposed by Allan Paivio (Paivio, 1975; Paivio, 1990; Paivio, 1991; Clark \& Paivio, 1991), and it was suggested that cognition depends on two independent but connected systems - i.e. verbal and non-verbal coding. Based on several authors' works (Clark \& Paivio, 1991; Rowe \& Paivio, 1972; Sadoski, 2005), the following can be concluded:

- The verbal system is concerned with the representing and processing of language. Its building blocks are so-called logogens. This system perceives written and spoken language codes as the primary forms of its representation.

- The non-verbal system is concerned with experiences, events, sensory memories (i.e. sound, smell, taste, etc.), and emotions. Its basic building blocks are so-called images. This system perceives imagery as a primary form of its representation.

Both these systems can be activated independently of each other - either by external or internal stimuli - for instance, recognition, manipulation, and/or thinking about specific things, objects, words, etc. According to Paivio (2006), the most beneficial is so-called referential processing - i.e. when both

\footnotetext{
${ }^{1}$ Constantine the Philosopher University in Nitra, Faculty of Education, Department of English Language and Culture, Nitra, Slovakia, janey.kamenicka@gmail.com
} 
systems are activated, and connections are made between them, as the processing of the incoming stimuli happens between the two of them. Such processing enables a linguistic reference to be assigned to a picture, as well as mental images to be assigned to words.

In order to understand this phenomenon, we can imagine an apple. In the level of verbal code, the word apple represents an object without any intrinsic connections to it. Yet, in the level of non-verbal code, the image of an actual apple, which grew on the specific apple tree in your parents' garden, can appear in your mind - along with several additional images, which can include its color, smell, taste, and experiences and memories from your childhood you had, which concern that apple tree the specific apple grew on.

If such double-coding of an incoming stimulus is achieved, it leads to better chances of remembering. Sadoski \& Paivio (2013) emphasize the importance of repeated encounters of imagens and logogens as it is the experience, which modifies the structure and processing potential of dual coding. However, if one of the two systems fails to retrieve the information from memory, the other system can compensate for the low activity of the first one and deliver the information (Paivio \& Clark, 1986; Paivio \& Walsh, 1993). This is thanks to images, words, phrases, and sentences, which operate as memory pegs (e.g. Begg, 1972; Dilley \& Paivio, 1968; Paivio, 1965; Sadoski, 1985).

In order to graphically demonstrate the Dual Coding Theory supported by the above-mentioned authors, we provide the following scheme:

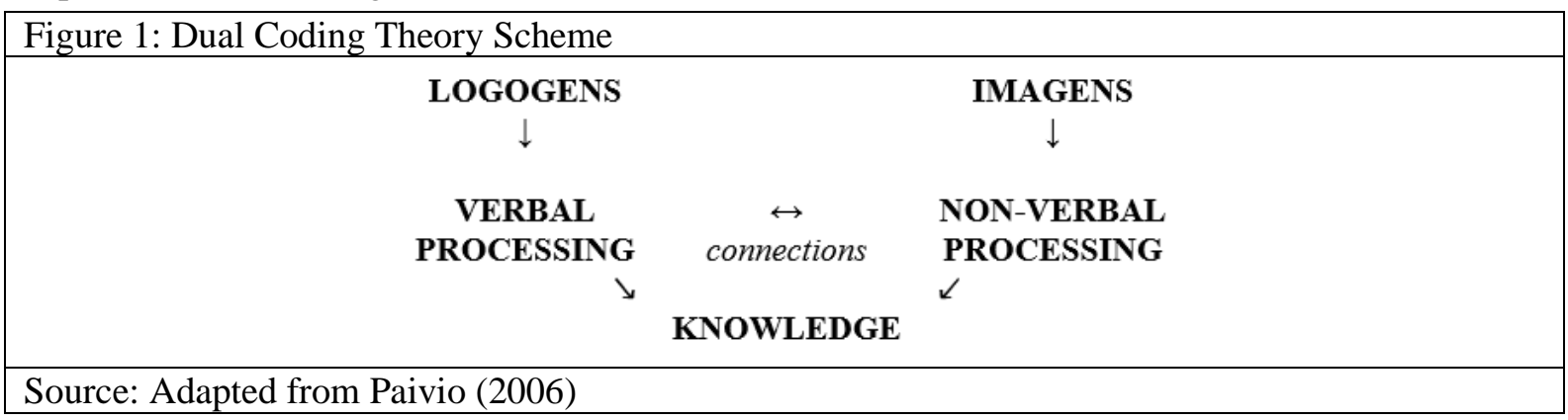

With regard to foreign language learning, Paivio (2006) suggests that activities during which learners form mental images improve the comprehension of the text as well as vocabulary recall. Furthermore, learners of various age groups (from primary school to university) benefit from the combination of verbal items and non-verbal items - in terms of comprehension and learning from texts. To add, in terms of high-level performances, Ericsson (1996) emphasizes the importance of practice - which, in this context, includes both verbal and non-verbal systems.

In summary, the concept of dual coding deals with the existence and the cooperation of the two systems, verbal and non-verbal. Yet, the example which was offered with the apple implies that there exists a third entity, which enhances deeper processing. We consider emotions as the third entity, which role has been hinted at above, however, according to the works cited, it was perceived as one of the elements of the non-verbal system of imagens. As it was implied by several authors (Paivio, 1975; Paivio \& Lambert, 1981; Paivio, 2006), it is believed that the non-verbal code (including emotions) is even stronger than the verbal one. Or rather, the non-verbal code enhances memory traces more significantly than the verbal code. The role of non-verbal code (esp. in the form of emotions) in memory formation and cognitive processes will be discussed in more detail in the section dealing with the proposed Apple Tree Model.

\section{Levels of Processing Theory}

Another theory, which forms a basis for our Apple Tree Model, is the concept proposed by Craik and Lockhart (1972) - who proposed that in order to sufficiently proceduralize and remember information, deep processing and creation of individual mental structures are necessary. The authors of this theory proposed that only semantic processing (i.e. deep mental processing, which involves a deep analysis of the information we want to remember) enables individuals to recall a stimulus. They also suggested that it is only through semantic processing that strong, elaborate and long-lasting memory traces can be formed.

The authors of this concept proposed that there are two levels of processing, namely, Type I processing and Type II processing. According to this theory, Type I includes structural processing - which is 
concerned with how things look like, and phonetic processing - which is concerned with tunes and voices. This type of processing is believed to be shallow, as it leads to fleeting memories, and such stimuli are stored in short-term memory (Schulman, 1971; Treisman, 1964). Type II includes semantic processing - which is concerned with deeper mental processing of the meaning of the incoming information. This type of processing is believed to be deeper, as it leads to long-term storage of information in the memory (Schulman, 1971; Treisman, 1964; Craik and Lockhart, 1972).

The authors (Craik and Lockhart, 1972) of this concept emphasize the fact that several factors influence how well the information will be stored in memory and thus affect the subsequent retention. The factors mentioned include the meaningfulness of the information to be remembered, the attention devoted to the incoming stimulus, familiarity with the topic, and last but not least, the time available for processing. To add, an interesting phenomenon suggested by the authors of this concept is that people have a longterm memory for non-verbal information, such as pictures, faces, tunes, and voices.

With regard to the research findings provided by Craik and Lockhart (1972), Schulman (1971), Treisman (1964), and Glanzer (1972), who can be considered as advocates of the Levels of Processing Theory, we provide the following scheme of this theory:

\begin{tabular}{|c|c|c|c|c|}
\hline Type I $\rightarrow$ & $\begin{array}{c}\text { SHORT-TERM } \\
\text { MEMORY } \\
\text { STRUCTURAL } \\
\text { PROCESSING } \\
\downarrow\end{array}$ & $\begin{array}{c} \\
\\
\\
\\
\\
\text { SEMANTIC } \\
\text { PROCESSING } \\
\text { Type II } \\
\downarrow \downarrow \downarrow \\
\text { LONG-TERM } \\
\text { MEMORY }\end{array}$ & $\begin{array}{l}\text { SHORT-TERM } \\
\text { MEMORY } \\
\text { PHONETIC } \\
\text { PROCESSING } \\
\swarrow\end{array}$ & $\leftarrow$ Type I \\
\hline
\end{tabular}

In order to achieve the deep semantic processing of the information in the context of foreign language learning, it is essential not to forget the important role of repetition and language drills. Nevertheless, mindless repetition of material does not enhance learning if the learner lacks the intention to learn (Tulving, 1966). Thus, it is especially important to pay attention to the meaningfulness of the activities in foreign language classes as well as their relation to real-life use.

\section{Emotion-Involved Processing Hypothesis}

Based on the above-mentioned cognitive theories, Kanazawa (2020) proposed the Emotion-Involved Processing Hypothesis, which also serves as the basis for our Apple Tree Model of Emotion-Involved Processing, which is discussed in the following section. Kanazawa (2020) suggested that emotioninvolved processing, which significantly aids long-term retention, is an even deeper level of cognition than semantic processing. This theory is schematically summarized in the Figure 3.

\begin{tabular}{|c|c|}
\hline \multicolumn{2}{|c|}{ Figure 3: Emotion-Involved Processing Hypothesis Scheme } \\
\hline DEPTH OF PROCESSING & TYPE OF PROCESSING \\
\hline shallow & Perceptual \\
\hline & $\downarrow$ \\
\hline medium & Semantic \\
\hline & $\downarrow \downarrow$ \\
\hline deep & Emotion-Involved \\
\hline & $\downarrow \downarrow \downarrow$ \\
\hline & LONG-TERM RETENTION \\
\hline
\end{tabular}


This concept was probably based on the previous research findings when Ferré (2003) experimentally verified and confirmed that the emotionality of lexical items could influence their further processing and learning. The data suggested that with regard to foreign language vocabulary learning, the lexical valence of particular lexical items was a very significant element - the lexical valence is considered as perceived (subjective) emotionality of lexical items by learners. Later studies dealing with this concept confirmed the above-mentioned research findings (Ayçiçeği \& Harris, 2004; Ayçiçeği-Dinn \& Caldwell-Harris 2009).

Last but not least, the author of the Emotion-Involved Processing Hypothesis (Kanazawa, 2016) conducted a similar experiment dealing with how learning (i.e. incidental retention and recall) of individual foreign language vocabulary items can be affected by their lexical valence. When words of positive and negative lexical valence were compared, it was found that words with positive lexical valence were learned significantly better than those with negative lexical valence - which emphasizes the importance and beneficial effects of positive emotional stimuli and associations in the process of learning.

\section{Apple Tree Model of Emotion-Involved Processing}

With the progress in research in the field of cognitive processes, the research findings suggest that emotions are a significant element of learning, including foreign language learning (see previously discussed concepts). However, with regard to education, we do not attribute emotions to the perceived emotional valence of individual vocabulary items only. Rather, we understand them as more complex psychological elements, i.e. the emotionally competent stimuli - which have the ability to penetrate every level of processing, including the deepest one, i.e. emotion-involved processing (proposed by Kanazawa, 2020).

\section{Emotionally Competent Stimuli}

Emotionally competent stimuli (ECS) (Král'ová, Kamenická, \& Tirpáková, forthcoming A), which are also known as emotionally charged events (Gallo, 2014), are considered as the best-processed form of external stimuli for the human brain, which have ever been measured (Medina, 2008). As the human brain perceives thousands of sensory inputs, it has to sort out which of those stimuli are worth giving attention and further processing. It is thanks to the reticular activating system, which acts as the brain's filter, that the stimuli flavored with personal relevance, novelty, and emotions are considered as important (Kelly, 2015). In fact, stimuli, which are emotionally significant, are remembered with more clarity than the stimuli, which are emotionally neutral (Greenspan \& Shanker, 2004; Medina, 2008; Todd, 2013).

Research done in this area suggests that positive emotions experienced during the encoding of information can enhance its subsequent retrieval in the future (Bower, 1981; Singer and Salovey, 1988). Similarly, with regard to foreign language vocabulary storage and recall, Thornburry (2002) suggests that effective information, which is stored along with cognitive data, may be equally important.

\section{Research}

The studies we conducted on the interplay of emotion and cognition in the context of foreign language learning dealt with the effect of emotionally competent stimuli on foreign language vocabulary retention and recall in various research contexts.

The action research conducted in 2019 (Kamenická and Kováčiková, 2019), when we effectively stimulated secondary grammar school foreign language learners in order to help them with learning, confirmed that emotional engagement of learners eliminated their boredom and brought positive emotions during foreign language classes. This research was done with regard to VAK learning styles i.e. visual, auditory, and kinesthetic, as classified by Scrivener (2011). The findings suggest that all of the three learning styles benefited from the implement emotionally competent stimuli (ECS), including the kinesthetic one, which is often forgotten and neglected during traditional classes. In the feedback questionnaire, the research participants suggested that ECS implemented provided them with a meaningful context for the vocabulary items learnt, as they often missed it in the FL textbook they were using - and as a result, that helped them with the retention and recall of new vocabulary. These research findings imply that ECS might be an answer to how to engage all learning styles at once, and as a result, improve their retention and recall of foreign language vocabulary items. 
Based on the previously mentioned research findings, we conducted similar research of an experimental nature (Král'ová, Kamenická, \& Tirpáková, forthcoming B) with university students. To ensure validity and reliability, for this research, a more detailed classification of learning styles, which was based on multiple intelligence types, was used (McKenzie, 1999 - translated and adapted by I. Turek). The previous research findings were confirmed experimentally - as the knowledge of foreign language vocabulary items increased among participants of all learning styles in the experimental group, where ECS were implemented in FL classes. When compared to the control group, the improvement was approximately twice as large. An interesting finding is that among experimental group participants, mostly those of musical and kinesthetic learning styles profited from effective intervention. In fact, these two learning styles are mostly neglected during traditional classes. Another finding worth attention is that among control group participants, the greatest increase was detected among participants with logical learning styles. However, it is necessary to mention that learning styles occur in combination among learners of both groups, i.e. there is no one who can be considered as a pure representative of one learning style only. In this experiment, interestingly, the intrapersonal learning style was most prevalent (in combination with other learning styles) among learners of both experimental and control groups. With regard to this finding, more research would be beneficial - to find out if there is a general dominance of intrapersonal learning style, as opposed to interpersonal learning style, in the human population.

Another study of a mixed qualitative-quantitative nature was conducted (Králová, Kamenická, \& Tirpáková, forthcoming A), which dealt with the verification of how ECS affects foreign language vocabulary retention, emotional status and autonomic stress response of university students. The comparison of vocabulary pre-test and post-test results, which was used to detect the declarative vocabulary knowledge, revealed that the improvement was more than double in the experimental group - in comparison to the control group. However, the comparison of speaking pre-test and post-test results, which was used to detect the procedural vocabulary knowledge, revealed no statistically significant improvement. Concerning the general emotional states of research subjects, which were monitored using the Emotional Habitual Subjective Comfort Scale (Džuka \& Dalbert, 2002), no statistically significant difference between pre-test and post-test was found. However, the analysis of the Emotional Habitual Subjective Comfort Scale (Džuka \& Dalbert, 2002) pre-tests and post-tests, which was used to monitor learners' specific emotional states bound to FL learning, revealed an increase in foreign language enjoyment in both groups, with the increase in the experimental group being twice as large - when compared to the control group. Concerning the stress responses and stress release during the post-test, the heart rate measurement did not reveal any statistically significant differences. The feedback questionnaires analysis revealed that the research subjects considered ECS as their favorite part of the EFL class. They also claimed that during future classes, they would appreciate more of them. Furthermore, it was revealed that research participants recognized their value mostly because they were fun and multi-sensory. As they suggested, this has also helped them with foreign language vocabulary learning.

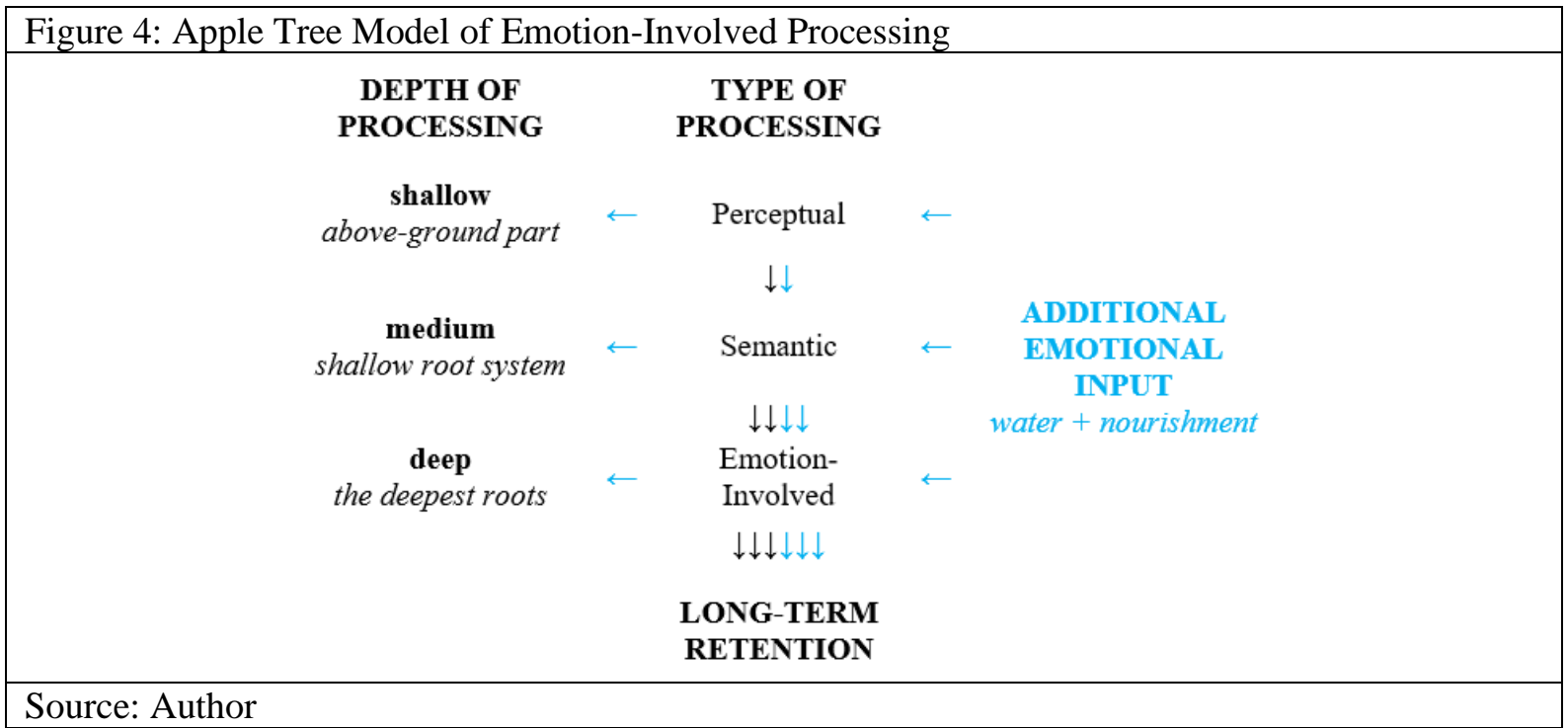




\section{The Apple Tree Model}

The above-mentioned research findings emphasize how important the role of the teacher is in the regulation of the learning atmosphere in the class (Horwitz, Horwitz and Cope, 1986). The cognitive theories, as well as the research findings we discussed above, lead us to the proposition of the Apple Tree Model of Emotion-Involved Processing. We provide a graphical summary of this theory in the Figure 4.

The ECS included in education make it easier for learned information to pass from the shallow to the deep levels of processing and act as the water and nourishment, which every tree needs to survive and bear high-quality fruits. Although both moisture and nourishment occur in soil naturally, only a caring gardener knows exactly what the tree needs to ensure the best harvest possible. In an educational context, it is the teacher who has the greatest responsibility for the sufficient watering and nutrition of the trees in their gardens, or rather, for the regulation of the learning atmosphere in the class (Horwitz, Horwitz and Cope, 1986). This is what reaches the deepest root system of the tree and supports not only its foundations but also the tree as a whole. Similarly, as a gardener with his watering can full of water and important nutrition, the teacher can use positive ECS to support the mental foundations of their learners and ensure the cognitive harvest.

Regarding the various classifications of learning styles (e.g. Scrivener, 2011; McKenzie, 1999), it is usual that in one garden, apart from apple trees, there are more types of fruit trees, too. Thus, the gardener needs to provide specialized care for every single one of them. If there existed a universal nutrient, which would be suitable for every type of tree in his garden, it would make them extremely happy because it would make their jobs significantly less demanding. As suggested by the previously mentioned research done in the area of foreign language learning, the ECS might be considered as such, a universal nutrient - especially because they can reinforce emotional engagement and enhance subsequent foreign language vocabulary retention and recall.

\section{How to Deliver Meaningfulness and Achieve Addictiveness}

Research, which dealt with factors influencing the effectiveness of mathematics education at secondary schools (Pelikán, 2011), revealed that only when the content taught was built into an example that evoked situations from everyday life or future professions, the learners considered the information taught as important and useful in the future. Similarly, Greenspan and Benderly (1997) suggest that authentic and real-world tasks enhance students' motivation to learn. Furthermore, motivation has often been linked to emotional experiences (Frick, 2015).

Therefore, for teachers, the most important aspect of teaching is to reflect upon the content they teach and how they teach it. It is especially important to reflect if they are able to ignite a spark of curiosity in their learners and inspire them to find more information about the topic in which they are interested (Pelikán, 2011).

Thus, in the context of foreign language education, to achieve meaningfulness and to ignite the abovementioned spark in learners, the principle of ' 3 reals' should be applied - using real language in real contexts, learners should be taught about real life (Kamenická, 2019). The foreign language should be used as a means of learning something more, of learning something beyond the language itself, of learning relevant content, in which value both learners and teachers believe in. If such a spark is ignited, it will be easier for learners to engage with the activity, which can eventually become their hobby, and they will be yearning to spend some time with it every day - often unaware of the fact that they are learning a FL outside of the class. We propose several ways how this spark can be ignited - with emphasis on the fact that they can be used both inside and outside of foreign language class:

\section{Through Stories}

Everyone understands stories because they are based on cause-and-effect elements. This brings tension and excitement - and makes the reader/listener want to know what follows. Moreover, the reader/listener can identify with its characters, which enhances the emotional engagement.

With regard to foreign language learning, the following types of stories are advised to be used (Kelly, 2016; Mixon \& Temu, 2006; Scrivener, 2011).

- personal stories - real or slightly dramatized (Scrivener, 2011), to help students to grow in "areas they intuitively know are crucial" (Kelly, 2016, p. 85), 
- stories, in which wisdom is hidden and which show the real moral values, for instance, Chicken Soup for the Soul series, Bruno Ferrero's series, and The Art of Happiness: A Handbook for Living (The Dalai Lama \& Cutler, 1999),

- national and local stories - the familiarity of learners with the background culture can reduce foreign language anxiety (Mixon and Temu, 2006),

- national and local stories from exotic countries - there is always something that can be learned from other cultures, and it sparks curiosity in learners at the same time,

- legends and fairy tales - the local or exotic, especially those, which are rare and not very famous,

- mystery and ghost stories - which are especially popular among teenagers,

- individual incidents from novels or biographies - the fact that they understand the novel written in a foreign language boosts learners' self-confidence,

- stories from newspapers and magazines, or their adapted versions - again, understanding such stories boosts learners' self-confidence and provides them with up-to-date information,

- individual incidents or versions of stories from movies and TV series.

With regard to various age groups of learners, the following types of stories are recommended (Kelly, 2016; Scrivener, 2011):

- young learners and teenagers - stories about friendship, devotion, love - both platonic and romantic, power and conflicts, understanding and seeing the world differently, kindness and helping, and stories about characters who have exceptional internal strengths.

- adult learners and working people - stories about social changes and tolerance, relationships, and motivating stories about perseverance and challenges of business leaders.

\section{Through Videos}

The following ideas put emphasis on real language, up-to-date lexical input, and real-life related information on a daily basis for foreign language learners. In order to let learners create and experience the foreign-language speaking environment, we propose that foreign language teachers both implement the following suggestions to their classes and advise their learners to:

- watch BBC News - learners not only learn about recent events in the world, but they also have an opportunity to experience the RP English, which is the UK pronunciation variety often seen as the standard one (Scrivener, 2011),

- watch public service announcements - videos, which contain a message for the general public, which aims to raise awareness of a social issue and thus to change people's attitudes and affect their behavior,

- watch movies in a foreign language - it is recommended to start with movies the learners are familiar with in their first language - this not only brings a feeling of safety and helps to avoid stressful situations, but they also realize that much can be lost in translations,

- watch TV series in a foreign language - the exciting storylines, interesting characters the learners adore and/or identify with, together with the fact that the individual episodes are released on a weekly basis, engage the learners to such extent that they do not even realize how addictive the TV series is,

- watch the qualitative foreign reality shows - not only do they deal with various topics of learners' possible interests, but they also provide them with specialized vocabulary in various areas including business, medicine, nature and environment, technical English, hobbies and lifestyle, etc.

- follow a YouTube channel - not only do there exist thousands of YouTube channels, every single one provides a foreign language learner with an unlimited source of vocabulary items in the field of their interest. Following the channel and watching the videos related to learners' hobbies eventually becomes a hobby itself. Not only do the videos tend to be very addictive, as they are released on a regular basis, they also provide learners with opportunities to experience various English accents, including those of native but also of non-native speakers. Since in the future, the foreign language learners might be expected to communicate with people of various cultural and national backgrounds - not only with people, who come from the UK and the USA, this is especially useful,

- explore the world through Google Maps and Street View - which can be followed by watching a YouTube video from a chosen area. Every person is naturally curious, so it is beneficial to 
choose a place on the map - a random one or somewhere more popular and peek there from above, using the satellite view of Google Maps, and/or explore it more closely, using Google Street View. This allows the exploration of various places, which can be both fun - you never know, what funny situations are caught on camera, but also very educating - for instance, archeological sites in Egypt and the effects of global warming at Kiribati.

\section{Through Games}

Regardless of the age of the learner, everyone loves games - although sometimes it might be difficult to admit, especially with adult learners of older age. Games provide learners, especially foreign language learners, with a safe learning environment, which reduces stress and anxiety simply because they are games - nothing serious is going on when playing.

In the educational environment, it is beneficial to use simulations of real-life situations, quizzes, or games when teamwork is required - even more if it is done using the target foreign language. A quick Google search on 'games for EFL class' will provide every teacher with countless ideas. In fact, teamwork is a soft skill, which will be required from learners in the future, as it teaches them to:

- be reliable,

- how to communicate effectively,

- plan,

- solve problems,

- make decisions,

- listen to and consider others' opinions,

- how to be tolerant and respectful towards others,

- resolve conflicts,

- be persuasive.

Moreover, such games can be even more educational for learners, who are too competitive and/or are strongly introverted or individualistic - as they teach them about the real value of teamwork. However, the games do not have to be included in the class only. They can be stretched beyond the framework of traditional school classes - especially games based on group work, which include the collecting of points - as it could be seen in Harry Potter movies and book series.

\section{Through Computer Games}

There could be a whole work dedicated to computer games and foreign language acquisition. In fact, they are one of the most effective ways to ignite the spark of interest in learners and, at the same time, promote foreign language learning to a different level. People of all ages spend their free time gaming - so it is advantageous to combine business with pleasure, or rather, to combine learning (not only foreign language) and pleasure from gaming as such.

Computer game producers are very well aware of how the human brain works, that is why they design them in such a way that they are very addictive. At the same time, they can be very helpful in foreign language acquisition. Thus, it can be concluded that when it comes to gaming and foreign language learning, the learner is stepping on very thin ice. Therefore, there should be some rules set by the learners themselves or by their parents, for instance:

- gaming will be allowed in a foreign language only,

- gaming will be allowed for a limited time,

- gaming will be allowed as a reward for an activity, e.g. for time spent studying or doing chores, etc.

At the same time, especially with young learners, their parents should be interested in what games their children play and take appropriate measures against unsuitable games if necessary. On the other hand, qualitative computer games can act as a vocabulary treasury, which will literally engrave the new vocabulary items to learners' memories - thanks to the emotional engagement experienced during the game. The vocabulary treasuries can be found in numerous games, we provide just a few examples:

- logical games - which include riddles and problem solving,

- historical games - which include real historical events,

- simulators - which deal with everyday life, flying, driving, etc., 
- interactive story games - which deal with interpersonal relationships and problem solving,

- games, which promote moral values and principles - those often include fighting against evil and human greed,

- mystery games - which are designed around inexplicable mystery or event,

- educational games - some of them teach foreign language vocabulary and require the player to find those items in pictures of messy rooms, gardens, etc.

\section{Reception and Production}

With regard to foreign language learning, the ideas proposed above are more of perception of the language than its production. As seen with babies, in the beginning, they learn their mother language by its perception first. Just then, they start to imitate their parents and produce syllables, words, phrases, and later, sensible sentences. This is how foreign language learners can benefit from receptive input they experience a foreign language environment, and their brains have space and suitable conditions to act like sponges - they absorb and store the information. Sometimes, it can be beneficial to tell a story or play a video to foreign language learners just for their enjoyment - without any subsequent comprehension tasks. This provides learners with relative safety and allows them to enjoy the content presented even more.

However, it is also essential to remember, that similarly as with babies, the receptive input needs to be followed by a productive output in the context of foreign language learning too. Therefore, for foreign language learners, it is beneficial to combine the above-mentioned ideas with activities that would elicit spoken or/and written productive responses. For instance:

- To practice the use of nouns, adjectives and basic verb forms and tenses, learners can be asked to describe a scene they saw. This is especially beneficial for FL learners at the beginner level, as it elicits basic vocabulary use.

- For grammar use practice, especially verb forms and tenses, description of events and retelling of the story is beneficial.

- With regard to the practice of conditionals as well as past and future tenses, it is convenient to ask learners to speculate about the events that might have preceded or might have followed the story or the content of the activity presented.

- To check learners' comprehension and in order to find out if and how they understand a certain problem or issue (e.g. social, cultural, historical, environmental, etc.), we recommend a group discussion.

- In order to connect the implemented activity used with students' own everyday reality, it is good to ask them to compare and/or contrast it with their own experiences or experiences of people who are close to them.

\section{Conclusion}

In conclusion, it was suggested that if foreign language learners believe in the meaningfulness and value of what they learn, their attention and motivation to learn will be enhanced. This can be achieved by delivering positive emotional stimuli during the process of foreign language learning in class but also out of class, i.e. in their free time. We would like to conclude this work with a quotation from an unknown author: "If you want to build a ship, don't drum up the men to gather wood, divide the work, and give orders. Instead, teach them to yearn for the vast and endless sea."

\section{Acknowledgements}

This work was supported by the grant KEGA 002UKF-4/2020 of the Ministry of Education, Science, Research and Sport of the Slovak Republic.

\section{References}

Ayçiçeği, A., \& Harris, C. (2004). Bilinguals' recall and recognition of emotion words. Cognition and Emotion, 18(7), 977987. doi:10.1080/02699930341000301

Ayçiçeği-Dinn, A., \& Caldwell-Harris, C. L. (2009). Emotion-memory effects in bilingual speakers: A levels-of-processing approach. Bilingualism: Language and Cognition, 12(3), 291-303. doi:10.1017/s1366728909990125

Begg, I. (1972). Recall of meaningful phrases. Journal of Verbal Learning and Verbal Behavior, 11(4), 431-439.

doi:10.1016/s0022-5371(72)80024-0 
Boers, F., \& Lindstromberg, S. (Ed.). (2008). Cognitive linguistic approaches to teaching vocabulary and phraseology. New York: Mouton de Gruyter.

Bower, G. H. (1981). Mood and memory. American Psychologist, 36(2), 129-148. doi:10.1037/0003-066x.36.2.129

Clark, J. M., \& Paivio, A. (1991). Dual Coding Theory and Education. Educational Psychology Review, 3(3), 149-210. doi:10.1007/bf01320076

Craik, F. I., \& Lockhart, R. S. (1972). Levels of processing: A framework for memory research. Journal of Verbal Learning and Verbal Behavior, 11(6), 671-684. doi:10.1016/s0022-5371(72)80001-x

Dalai-Lama, \& Cutler, H. C. (1999). The Art of Happiness: A Handbook for Living. Hodden and Stoughton.

Dilley, M. G., \& Paivio, A. (1968). Pictures and words as stimulus and response items in paired-associate learning of young children. Journal of Experimental Child Psychology, 6(2), 231-240. doi:10.1016/0022-0965(68)90087-8

Džuka, J., \& Dalbert, C. (2002). Vývoj a overenie validity Škál emocionálnej habituálnej subjektívnej pohody (SEHP)

[Elaboration and verification of emotional habitual subjective well-being scales (SEHP)]. Československá psychologie, 46(3), 234-250.

Ericsson, K. A. (1996). The Acquisition of Expert Performance: An Introduction to Some of the Issues. In K. A. Ericsson (Ed.), The Road To Excellence: The Acquisition of Expert Performance in the Arts and Sciences, Sports, and Games (pp. 150). Psychology Press.

Ferré, P. (2003). Effects of level of processing on memory for affectively valenced words. Cognition \& Emotion, 17(6), 859880. doi:10.1080/02699930244000200

Frick, T. (2015). Emotions, Learning, and Good Teaching. Retrieved February 20, 2021, from https://www.researchgate.net/publication/295252290_Emotions_Learning_and_Good_Teaching

Gallo, C. (2014). Talk Like TED. New York: Macmillan.

Glanzer, M. (1972). Storage Mechanisms in Recall. Psychology of Learning and Motivation, 129-193. doi:10.1016/s0079$7421(08) 60441-7$

Greenspan, S. I., \& Benderly, B. L. (1997). The Growth of the Mind and the Endangered Origins of Intelligence. Reading: Addison-Wesley.

Greenspan, S. I., \& Shanker, S. G. (2004). The first idea: How symbols, language, and intelligence evolved from our primate ancestors to modern humans. Da Capo Press.

Horwitz, E. K., Horwitz, M. B., \& Cope, J. (1986). Foreign Language Classroom Anxiety. The Modern Language Journal, 70(2), 125-132. doi:10.1111/j.1540-4781.1986.tb05256.x

Kamenická, J. (2019). How to Enjoy the Journey: Foreign Language Vocabulary Learning and Teaching. Slavonic Pedagogical Studies Journal, 8(2), 277-295. doi:10.18355/pg.2019.8.2.2

Kamenická, J., \& Kováčiková, E. (2019). Emotional Engagement in Teaching English Vocabulary. Praha: Verbum.

Kanazawa, Y. (2016). Micro-level emotion as a factor of L2 vocabulary memory: The effect of lexical emotional valence on incidental recall performance. Language Education \& Technology, 53, 23-52.

Kanazawa, Y. (2020). Emotion as "deeper" than cognition: Theoretical underpinnings and multidisciplinary lignes de faits to the Emotion-Involved Processing Hypothesis (EIPH). Journal of International Studies, 9(1), 185-206.

Kelly, C. (2015). Motivation in English Teaching. MBALL. Retrieved February 20, 2020, from https://www.researchgate.net/publication/315816976_Motivation_in_English_Teaching

Kelly, C. (2016). The Neuroscience of Stories and Why Our Brains Love Them. Kobe City University of Foreign Studies Journal of Research Institute, 54, 73-90. Retrieved February 20, 2021, from https://core.ac.uk/download/pdf/83078872.pdf Králová, Z., Kamenická, J., \& Tirpáková, A. (Forthcoming A). Emotionally Competent Stimuli in Teaching Foreign Language Vocabulary.

Král'ová, Z., Kamenická, J., \& Tirpáková, A. (Forthcoming B). Emotional Stimuli in Teaching Foreign Language Vocabulary to Learners with Different Learning Styles.

McKenzie, W. (1999). Multiple Intelligences Inventory. Retrieved from http://surfaquarium.com/MI/inventory.htm McPherron, P., \& Randolph, P. T. (2014). Cat Got Your Tongue?: Teaching Idioms to English Learners. TESOL Press. Medina, J. (2008). Brain Rules. Seattle: Pear Press.

Mixon, M., \& Temu, P. (2006). First Road to Learning: Language through Stories. English Teaching Forum, 44(2), 14-19.

Paivio, A. (1965). Abstractness, imagery, and meaningfulness in paired-associate learning. Journal of Verbal Learning and Verbal Behavior, 4(1), 32-38. doi:10.1016/s0022-5371(65)80064-0

Paivio, A. (1975). Coding Distinctions and Repetition Effects in Memory. In G. H. Bower, Psychology of Learning and Motivation (pp. 179-214). Academic Press.

Paivio, A. (1990). Mental Representations: A Dual Coding Theory. Oxford: Oxford University Press. doi:10.1093/acprof:oso/9780195066661.003.0004

Paivio, A. (1991). Dual coding theory: Retrospect and current status. Canadian Journal of Psychology, 45(3), 255-287. doi:10.1037/h0084295 
Paivio, A. (2006). Dual Coding Theory and Education. Pathways to Literacy Achievement for High Poverty Children. Michigan: The University of Michigan School of Education. Retrieved February 20, 2021, from http://citeseerx.ist.psu.edu/viewdoc/download?doi=10.1.1.329.7319\&rep=rep1\&type=pdf

Paivio, A., \& Clark, J. M. (1986). The role of topic and vehicle imagery in metaphor comprehension. Communication \& Cognition, 19, 367-388.

Paivio, A., \& Lambert, W. (1981). Dual coding and bilingual memory. Journal of Verbal Learning and Verbal Behavior, 20(5), 532-539. doi:10.1016/s0022-5371(81)90156-0

Paivio, A., \& Walsh, M. (1993). Psychological processes in metaphor comprehension and memory. In A. Ortony (Ed.), Metaphor and Thought (pp. 2-307). Cambridge: Cambridge University Press. doi:10.1017/cbo9781139173865.016

Pelikán, J. (2011). Hledáni těžiště výchovy [Finding the Core Values of Education]. Praha: Karolinum.

Rowe, E. J., \& Paivio, A. (1972). Effects of noun imagery, pronunciation, method of presentation, and intrapair order of items in verbal discrimination. Journal of Experimental Psychology, 93(2), 427-429. doi:10.1037/h0032479

Sadoski, M. (1985). Commentary: The Natural Use of Imagery in Story Comprehension and Recall: Replication and Extension. Reading Research Quarterly, 20(5), 658. doi:10.2307/747949

Sadoski, M. (2005). A Dual Coding View of Vocabulary Learning. Reading \& Writing Quarterly, 21(3), 221-238. doi:10.1080/10573560590949359

Sadoski, M., \& Paivio, A. (2013). A Dual Coding Theoretical Model of Reading. In D. E. Alvermann, N. J. Unrau, \& R. B Ruddell (Eds.), Theoretical Models and Processes of Reading (pp. 886-922). International Reading Association.

Scrivener, J. (2011). Learning Teaching. Oxford: Macmillan Education.

Schulman, A. I. (1971). Recognition memory for targets from a scanned word list. British Journal of Psychology, 62(3), 335 346. doi:10.1111/j.2044-8295.1971.tb02044.x

Singer, J. A., \& Salovey, P. (1988). Mood and memory: Evaluating the network theory of affect. Clinical Psychology Review, 8(2), 211-251. doi:10.1016/0272-7358(88)90060-8

Thornburry, S. (2002). How to teach vocabulary. Essex: Pearson Education Limited.

Todd, R. (2013, February 25). Discussion with Carmine Gallo. Talk Like TED. (C. Gallo, Interviewer)

Treisman, A. (1964). Monitoring and storage of irrelevant messages in selective attention. Journal of Verbal Learning and Verbal Behavior, 3(6), 449-459. doi:10.1016/s0022-5371(64)80015-3

Tulving, E. (1966). Subjective organization and effects of repetition in multi-trial free-recall learning. Journal of Verbal Learning and Verbal Behavior, 5(2), 193-197. doi:10.1016/s0022-5371(66)80016-6

Yates, D. (1966). The Art of Memory. London: Routledge \& Kegan Paul. doi:10.1086/ahr/73.1.89 